\title{
Intra-peritoneal bupivacaine in management of post-operative shoulder tip pain following diagnostic laparoscopic procedure - a triple blind randomized control trial
}

\author{
A H M Makarimª, D M S T Gnanarathne ${ }^{\mathrm{b}}$, S Hemapriya ${ }^{\mathrm{c}}$
}

\begin{abstract}
Background: Post-operative shoulder-tip pain (STP) is a frequent complication following laparoscopy resulting in significant morbidity. This trial evaluates Intra-Peritoneal Bupivacaine (IPB) as a method of relieving post-operative STP.

Methods: Fifty-eight patients undergoing diagnostic laparoscopies were randomized to Group A (treatment) and Group B (control). Group A $(n=28)$ received $0.25 \%$ bupivacaine and Group B $(n=30)$ received an equal volume $(10 \mathrm{ml})$ of normal saline as an intra-peritoneal instillation in to the sub diaphragmatic space under direct vision. STP was recorded by using a visual analogue pain scale (VAS) at 0 hour, 4 hours, 8 hours of surgery, and at the time of
\end{abstract}

discharge. Post-operative morbidity was assessed by additional analgesia and time taken for independent mobilisation.

Results: The incidence rate of STP in control group (B) was $70 \%$ while only $25 \%$ (7 out of 28 ) had reported STP in treatment Group $(A)$, which is statistically significant $(P=$ $0.001)$. Both severity of STP $(P=0.004)$ and post-operative additional analgesia $(P=0.001)$ were significantly higher in control group (B). Group A had an early mobilization (Mean Hours 9.43). Among the adverse effects studied, only nausea was reported higher in Group $A(P<0.05)$.

Conclusion: Per-operative intra-peritoneal instillation with bupivacaine significantly reduces both frequency and severity of STP following diagnostic laparoscopy while improving post-operative morbidity.

Key words: shoulder tip pain, intra-peritoneal bupivacaine, laparoscopy, morbidity

Sri Lanka Journal of Obstetrics and Gynaecology 2019; 41: 42-48

DOI: http://doi.org/10.4038/sljog.v41i2.7886

a Senior Registrar in Obstetrics and Gynaecology, Castle Street Hospital for Women, Colombo, Sri Lanka.

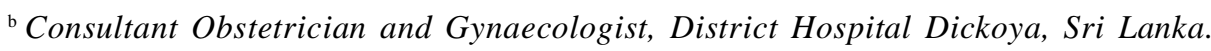

c Consultant Obstetrician and Gynaecologist, General Hospital Kandy, Sri Lanka.

Correspondence: AHM, e-mail: <makarimlk@gmail.com>

Received $12^{\text {th }}$ January 2019 and revised version accepted $8^{\text {th }}$ June 2019.

https://orcid.org/0000-0002-9311-7181

Competing interest: The authors report no conflict of interest

This is an open-access article distributed under the terms of the Creative Commons Attribution 4.0 International License, which permits unrestricted use, distribution and reproduction in any medium provided the original author and source are credited. 


\section{Introduction}

The occurrence of shoulder tip pain (STP) following laparoscopy varies from 35\%-80\% across patient populations in different studies ${ }^{1,2}$.

Mechanism of STP in laparoscopy was reviewed by Schoeffler, Diemunsch and Fourgeaud and they suggest rapid distension of peritoneum (due to introduction of $\mathrm{CO}_{2}$ ) possibly causes tearing of blood vessels and traumatic traction of the phrenic nerve. Hence, pain is perceived by releasing of inflammatory mediators ${ }^{3}$.

Several methods have been tried to reduce postoperative STP following laparoscopic procedures. Bilateral rectus sheath block performed at the level above the umbilicus with $15 \mathrm{ml}$ of $0.25 \%$ bupivacaine on each side ${ }^{4}$, application of local anaesthesia (lidocaine) under the diaphragm through a sub phrenic catheter (but with conflicting results) ${ }^{5,11}$, spinal anaesthesia ${ }^{6}$ and NSAID analgesia ${ }^{7}$ are few of those methods. Some researchers even tried with introduction of normal saline to sub phrenic space ${ }^{8}$.

The purpose of intra-peritoneal $0.25 \%$ Bupivacaine (IPB) administration is to block visceral nociceptive conduction by inhibiting sodium influx into nerve cells preventing depolarisation while providing an effective route of analgesia for postoperative shoulder tip pain ${ }^{5}$. Adverse reactions are rare when it is administrated correctly. Cardio toxicity when absorbed into systemic circulation and allergic reaction is not common. Other side effects are nausea, vomiting, vertigo, tinnitus, hypotension, bradycardia, and restless ${ }^{10}$. Literature review does not show that intra-peritoneal bupivacaine instillation is likely to mask the pain due to bowel perforation ${ }^{11,12}$.

\section{Rationale and justification}

Post-operative STP in laparoscopy is an important factor pertaining to morbidity according to the literature, as it causes shallow breathing of patient in immediate post-operative period which may result in reduced $\mathrm{O}_{2}$ saturation in blood, atelectasis and even pneumonia ${ }^{5}$. We have no data to say how common is the STP following laparoscopy in Sri Lanka. While relieving such pain might improve morbidity including quick recovery. Hence, one might be able to do diagnostic laparoscopy as a 'day-case surgery' in Sri Lanka.

\section{Materials and methods}

This is an institution based triple-blind randomised controlled clinical trial. This study was conducted in Teaching Hospital Kandy.

\section{Inclusion criteria}

Those who admitted for diagnostic laparoscopic procedures (including Dye test) were recruited for this study.

\section{Exclusion criteria}

- $\quad$ BMI $>25$

- Patients who underwent laparoscopy but with extra interventions (such as adhesiolysis, cystectomy)

- Laparoscopic procedure extended more than 45 min.

Clear written information was given in all 3 languages and informed consent was taken on admission. Sample size was calculated according to V. Kasiulevicinus \& V. Šapoka ${ }^{14}$,

Sample size $=\frac{\left\{\mathrm{P}_{1}\left(1-\mathrm{P}_{1}\right)+\mathrm{P}_{2}\left(1-\mathrm{P}_{2}\right)\right\}}{\left(\mathrm{P}_{2}-\mathrm{P}_{1}\right)^{2}} * \mathrm{f}(\alpha, \beta)$

P1 \& P2 - estimated outcome as proportion in control $\&$ treatment groups respectively

$\alpha$ - type I error level (0.05)

$\beta$ - type II error or statistical power (0.2)

$f(\alpha, \beta)=7.8489$ (from the table)

According to the previous studies conducted, P1 \& P2 are $28.6 \%$ and $63.3 \%$. Therefore, sample size is 58. Of which cases are 28 (2 were excluded due to extension of surgery more than $45 \mathrm{~min}$ ) and controls are 30. All patients were educated on how to use a visual analogue scale (VAS). 


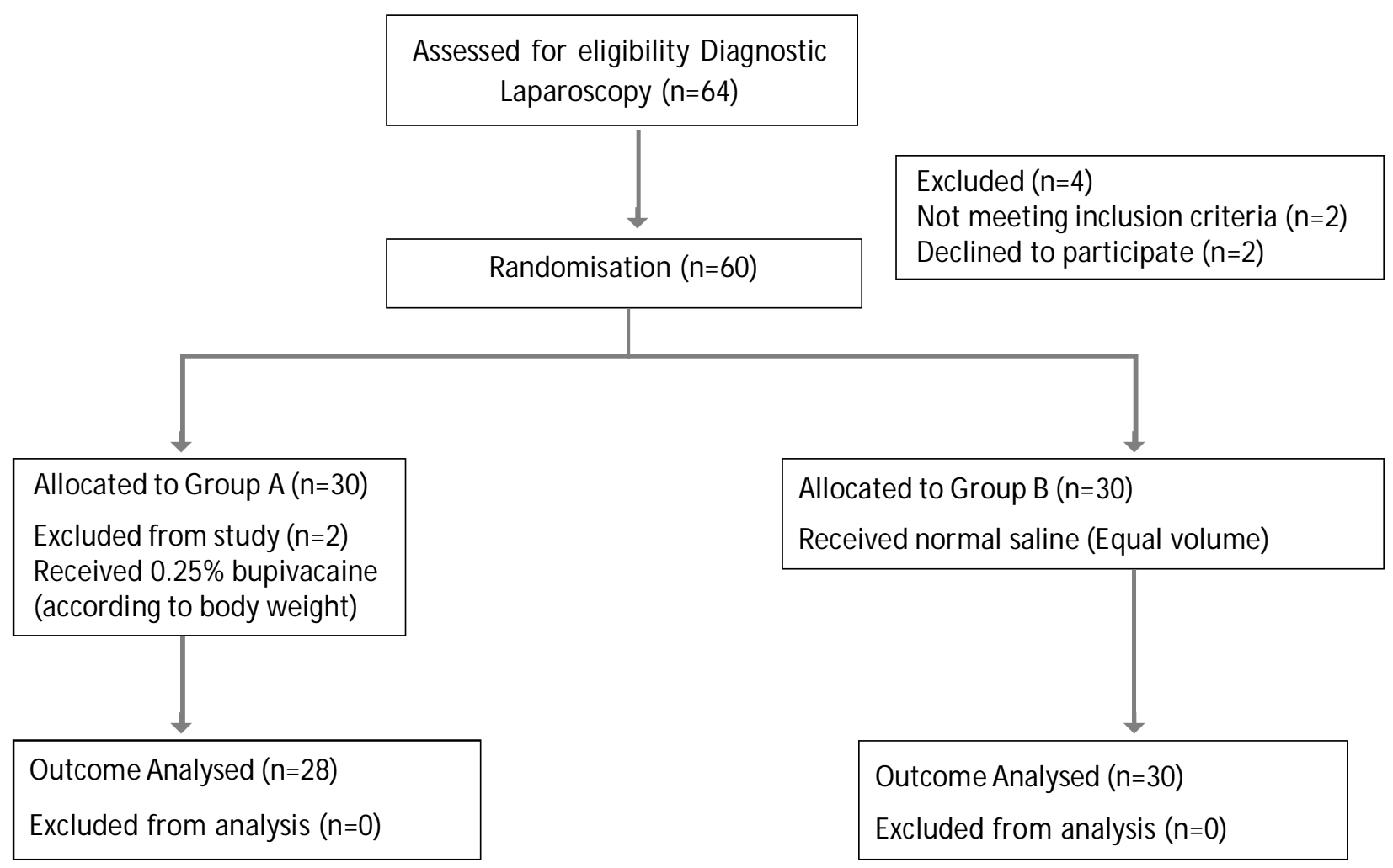

Figure. Consort chart of the trial

Simple randomisation was used by a computergenerated random number system (Excell-2010). Concealment was done by inserting the code into sealed opaque envelops by the House Officer. Envelopes were opened only after the anaesthesia by the Scrub Nurse and she prepared the syringe for instillation (either normal saline or bupivacaine accordingly). The patients were not aware about the group in which they belong to and the operator was not aware about the content of syringe. Hence, both the patient and the operator were blinded.

All laparoscopies were performed uniformly by the same operator with patients in modified Lloyd-Davies position under general anaesthesia. Pneumo-peritoneum was established by insufflation of $\mathrm{CO}_{2}$ under constant $10 \mathrm{mmHg}$ pressure and flow at a maximum of $3.5 \mathrm{l} / \mathrm{min}$. With $20 \mathrm{mmHg}$ of pneumo-peritoneum, the scope was introduced through the primary port, and the procedure was carried-out with $15 \mathrm{mmHg}$ of intra-abdominal pressure. After completion of procedure and before the removal of trocar, the laparoscopic injector (aspiration needle see Figure 1) was used for instillation of either $0.25 \%$ Bupivacaine (Group A) or normal saline (Group B) in to sub diaphragmatic space under direct vision. The volume of bupivacaine was calculated according to the body weight ( $2 \mathrm{mg} / \mathrm{kg}, 2.5 \mathrm{mg}$ per $\mathrm{ml}$ in $0.25 \%$ vial). Group B received equal volume of normal saline. Since the injector can retain about $6 \mathrm{ml}$ of fluid, we flushed it with equal amount of sterile distilled water $(6 \mathrm{ml})$ after the dose of either bupivacaine or normal saline. Then the residual $\mathrm{CO}_{2}$ was evacuated. Local infiltration of bupivacaine $(2.5 \mathrm{ml}$ of $0.25 \%$ ) was given to entry site in both groups identically to mask the pain due to entry site wound. Postoperative care was given uniformly to both groups according to the unit protocol.

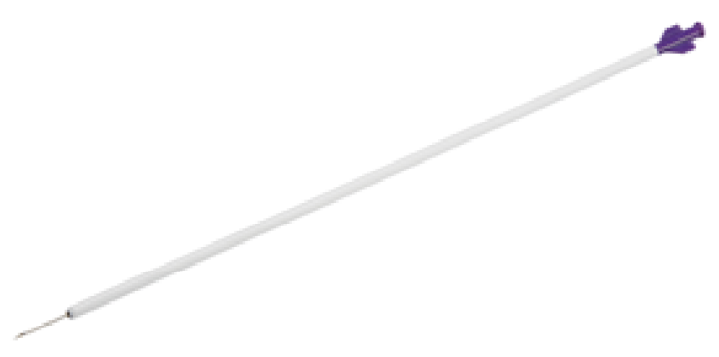

Figure 1. Laparoscopic aspiration needle. 
Zero hour $(0 \mathrm{hr})$ was taken as the time of arrival to the ward following surgery and the STP was assessed using the VAS at $0 \mathrm{hr}, 4 \mathrm{hr}$, and $8 \mathrm{hr}$ and on discharge (pain at discharge was assessed at ' 24 hours from 0 hour'). Those patients who had VAS $>4$, were administered diclofenac suppository (50 mg) as rescue analgesia. Resident doctors were involved in entering the pain intensity by the VAS (they were unaware about the intervention made). "Additional analgesia" was referred when the consumption of diclofenac $\mathrm{Na}$ exceeds 2 or more times by the patient during 24 hours of procedure.

In analysis of side effect profile of bupivacaine, vomiting, nausea and systolic hypotension were taken into consideration. Here, vomiting of 2 or more was considered and hypotension was defined as more than $15 \mathrm{mmHg}$ drop of post-operative systolic blood pressure from pre-operative value, which was monitored hourly for 8 hours from 0 hour by calibrated automated blood pressure device. Patients were asked to grade the severity of nausea $(1,2$, or 3$)$ and grade 3 was marked as 'nausea +'.

\section{Outcome measures}

Primary outcome measures were incidence of postoperative STP and severity of pain. Secondary outcome measures were morbidity of patients in terms of hospital stay (in hours), side effect profile of bupivacaine and use of additional analgesics in post-operative period.

\section{Statistical analysis}

Incidence of STP (VAS $>4$ is considered as 'Yes') was calculated as proportions and compared. Here null hypothesis was formulated as there is no difference in proportion of occurrence in pain in both groups. Then hypothesis was tested for significance. Chi square test was used and $P$ value $<0.05$ was taken as statis-tically significant.

Severity of STP in both groups were analyzed by the Student T test (unpaired). 'Additional analgesic consumption' was analyzed by two sample proportion tests and compared. Further, the Mann-Whitney U-test was used to analyze 'hours of hospital stay' and 'side effect profile of bupivacaine'. SPSS Version 21 was used for analysis.

\section{Ethical consideration}

Ethical approval of the study was obtained from ethical review committee of Teaching Hospital Kandy.

\section{Results}

58 patients were randomized to Group A and 30 patients were randomized to group $\mathrm{B}$

Table 1. Demographic and surgical data (Mann-Whitney U test)

\begin{tabular}{|l|l|l|c|}
\hline & \multicolumn{1}{|c|}{ Age } & \multicolumn{1}{|c|}{ BMI } & $\begin{array}{c}\text { Duration of } \\
\text { lap (in min) }\end{array}$ \\
\hline Group A & $30.85 \pm 4.17$ & $22.5 \pm 2.2$ & $30.0 \pm 5.8$ \\
Group B & $31.57 \pm 4.98$ & $23.0 \pm 2.5$ & $32.2 \pm 6.0$ \\
P value & 0.695 & 0.361 & 0.717 \\
\hline
\end{tabular}

There is no statistical difference in age, BMI and duration of laparoscopic procedure among 2 groups tested in this study $(\mathrm{P}>0.05)$.

Table 2. Overall incidence of STP

\begin{tabular}{|l|c|c|}
\hline & $\begin{array}{c}\text { Group A } \\
(\mathrm{n}=28)\end{array}$ & $\begin{array}{c}\text { Group B } \\
(\mathrm{n}=30)\end{array}$ \\
\hline Pain & $7(25.0 \%)$ & $21(70.0 \%)$ \\
No pain & $21(75 \%)$ & $19(30 \%)$ \\
\hline
\end{tabular}

Overall, only 7 out of 28 (25\%) in Group A and 21 out of $30(70 \%)$ in Group B had the STP which is statistically highly significant $(\mathrm{P}=0.001)$ according to Chi square test.

Table 3 shows that significant pain occurs at 4 and 8 hours in both groups.

Table 3. Pain at different times

\begin{tabular}{|l|c|c|}
\hline & Group A (n=28) & Group B (n=30) \\
\hline 0 Hours & $1(3.6 \%)$ & $4(13.3 \%)$ \\
4 Hours & $7(25 \%)$ & $16(53 \%)$ \\
8 Hours & $3(10.8 \%)$ & $15(50.0 \%)$ \\
Discharge & 0 & $4(13.3 \%)$ \\
Overall & $7(25.0 \%)$ & $21(70.0 \%)$ \\
\hline
\end{tabular}


Table 4. Severity of STP (Student's T test)

\begin{tabular}{|l|c|c|c|c|c|}
\hline & $\mathrm{N}$ & Mean VAS & $\begin{array}{c}\text { SD (Standard } \\
\text { Deviation) }\end{array}$ & $\begin{array}{c}\text { SEM (Standard } \\
\text { error of Mean) }\end{array}$ & P-value \\
\hline Group A & 28 & 3.86 & 1.53 & 0.290 & 0.004 \\
Group B & 30 & 6.21 & 1.83 & 0.346 & 0.004 \\
\hline
\end{tabular}

Severity of STP following laparoscopy among 2 groups were compared by unpaired $\mathrm{T}$ test for significance and there is a significant higher severity of pain was reported in Group B ( $\mathrm{P}=0.004)$.

\section{Post-operative morbidity}

This was assessed by additional analgesic consumption, early mobilization and side effect profile of bupivacaine.

Table 5. Additional analgesic consumption

\begin{tabular}{|l|l|c|c|c|}
\hline & & Group A & Group B & Chi square test \\
\hline Additional & Not given & 21 & 10 & $\mathrm{P}=0.003$ \\
analgesia & given & 7 & 20 & \\
\cline { 1 - 3 } Total & & 28 & 30 & \\
\hline
\end{tabular}

Additional analgesic consumption after the laparoscopy was significantly high (Chi square test) in Group B (P-value is 0.003).

Table 6. Side effect profile

\begin{tabular}{|l|c|c|c|}
\hline Side effect profile & Group A & Group B & T-Test \\
\hline No side effects & 10 & 22 & \\
Nausea & 13 & 6 & $\mathrm{P}=0.013$ \\
Vomiting & 3 & 1 & $\mathrm{P}=0.374$ \\
Hypotension & 2 & 1 & $\mathrm{P}=0.423$ \\
\hline
\end{tabular}

Nausea was the only side effect seen significantly higher in Group A $(\mathrm{P}<0.05)$.

Table 7. Hospital stay (in hours) (Chi Square test)

\begin{tabular}{|l|l|l|l|l|c|}
\hline & $\mathrm{N}$ & Mean (hours) & SD & SEM & $\begin{array}{l}\text { Sig (2-tailed } \\
\text { T-Test) }\end{array}$ \\
\hline Group A & 28 & 9.43 & 2.008 & 0.379 & 0.002 \\
Group B & 30 & 13.36 & 2.984 & 0.564 & 0.002 \\
\hline
\end{tabular}


Here, the time taken to mobilize independently from the bed was calculated as 'Hospital stay' in hours. However, all patients were kept for at least 24 hours from the laparoscopy to complete the study protocol.

\section{Table 8. Sub-group analysis (Cross-tabulation)}

\begin{tabular}{|l|c|c|}
\hline Duration of stay & Group A & Group B \\
\hline Up to 10 hours & $85.7 \%(24)$ & $23.26 \%(7)$ \\
$>10$ hours & $14.3 \%(4)$ & $76.7 \%(23)$ \\
\hline
\end{tabular}

When this is analyzed by chi-square test, [ $\mathrm{X} 2$ value $=23.26, \mathrm{P}=<0.001$, OR $=22$ (95\% CI 5.4788.42)], patients who were given bupivacaine are at least 5.47 times likely to be discharged early than not given. Hence, bupivacaine has significantly shortened the post-operative hospital stay.

\section{Discussion}

In order to minimize confounding errors, these laparoscopies were performed by same operator (Resident Obstetrician) and uniformity in procedure, intraabdominal pressure and gas flow rate were maintained. Our study showed that overall incidence of STP following diagnostic laparoscopy in control group was $70 \%$, which is comparable with previous studies $(35-80 \%)^{1}$. So, it is a very common complication than we see in our clinical practice. Another main finding in this study was, most patients experienced the STP at 4 and 8 hours after the surgery. It is a valuable information when one contemplates this as a day-case procedure. One could then, formulate a logical pain relief plan upon discharge.

Pain at Ohour was not different among 2 groups $(\mathrm{P}=0.09$ as 2 -tailed significant test was 0.179$)$ in occurrence and severity. This might be well explained by the effect of anesthetic drugs given during the procedure. Not only the incidence, but the severity too was noted to be higher in control group. Mean VAS in Group A and Group B were 3.86 and 6.21 respectively. Even though the perception of pain is highly subjective and many confounders can influence the outcome, every step had been taken to minimize those effects. Meanwhile, patients were specifically asked about the STP, not the abdominal pain. Fortunately, no one had any significant abdominal pain due to the procedure and the pain other than STP was managed according to the standard post-operative care.

We selected $0.25 \%$ bupivacaine as intra-abdominal analgesia for this study because of its safety, potency, feasibility and prolonged duration of action (half-life is between 5 and 16 hours) ${ }^{11}$. Instillation of bupivacaine required only a minimal skill. In this study, we found out that the bupivacaine is more effective than normal saline in alleviating STP following diagnostic laparoscopy.

Outside this study, usually most of our patients do not complain of STP. Because they may think this is 'normal' after the procedure or complain as 'nonspecific pain'. This might be one of the reasons why we do not see STP as common as reported.

Mean post-operative hours confined to bed in Group $\mathrm{A}$ and group B were 9.40 and 13.30 respectively $(\mathrm{P}=0.002)$. Approximately $85 \%$ of patients in Group A got out of bed independently before 10 hours, while only $23 \%$ in Group B was able to do so. Hence, those who were given bupivacaine is at least 5 times more likely to mobilize (discharge) earlier than control (95\% CI 5.47-88.42).

One fourth of patients in Group A and two third of patients in Group B had taken additional analgesia (as diclofenac Na $50 \mathrm{mg}$ suppositories) within 24 hours of procedure. Both percentages were compared by $\mathrm{T}$-Test and there was again significant increase in need of analgesia in control group $(\mathrm{P}=0.003)$.

In order to assess the side effect profile of bupivacaine, nausea, vomiting and hypotension (which are more frequent adverse effects of bupivacaine reported in literatures ${ }^{9,10}$ ) are analyzed. Bupivacaine group had significantly higher incidence of nausea $(\mathrm{P}=0.006)$ than control group, while other side effects were similar in both groups. Even though, nausea is non-specific symptom, it is the commonest side effect of bupivacaine in our study.

There were no demographic factors influencing the incidence of STP such as age and BMI. According to the previous works, residual gas left-in situ, time of procedure and intra-abdominal pressure might have influenced the incidence of $\mathrm{STP}^{13}$, but these factors were minimized by randomization and maintaining the uniformity in both groups. 
Main limitations encountered in this study are, previous abdominal surgeries were not considered as a confounding factor in analysis, only STP was asked, intervened and analyzed but other post-operative pain might influence the perception of STP and long-term implications were not studied if any.

\section{Conclusion and recommendation}

STP is very common following laparoscopy (70\%) and this might adversely affect short term morbidity. IPB is an effective, and safer method to relieve postoperative STP without any significant side effects. IPB has reduced post-operative additional analgesic consumption and enable early mobilization. We recommend to conduct similar type of study in operative laparoscopies and review them at regular set-interval to analyze long-term complications if any. It would be much better to include a Patient Satisfaction Questionnaire in future studies to express their views and experience to understand the fact further.

\section{References}

1. Tsai H, Chen Y, Ho C, et al. Maneuvers to Decrease Laparoscopy-Induced Shoulder and Upper Abdominal Pain: A Randomized Controlled Study. Journal of Surgery 2011; 146(12): 1360-66.

2. Hohlrieder M, Brimacombe J, Eschertzhuber S, Ulmer H, Keller C. A study of airway management using the ProSeal LMA laryngeal mask airway compared with the tracheal tube on postoperative analgesia requirements following gynaecological Laparoscopic surgery. Anaesthesia 2007; 62(9): 913-8.

3. Schoeffler P, Diemunsch P, Fourgeaud L, et al. Coelioscopieambulatoire. Cahiers d'Anesthsiologie 1993; 41: 385-91.

4. Smith BE, Suchak M, Siggins D, ChallandsJ. Rectus sheath block for diagnostic laparoscopy. Anaesthesia 1988; 43: 947-8.

5. Goegler S, Blobner M, Busley R, Felber AR. Subphrenic catheter for post-operative analgesia after laparoscopic cholecystectomy. Anaesthesia 1993; 79: A26.

6. Silva PD, Kang SB, Sloane KA, Gamete intrafallopian transfer with spinal anaesthesia. Fertility and Sterility 1993; 59: 841-3.

7. Wilson YG, Rhodes M, Ahmed R. Intra muscular diclofenac sodium for post-operative analgesia after laparoscopic cholecystectomy: a randomised controlled trial. Surgical Laparoscopy and Endoscopy 1994; 4: 340-4.

8. Seo YK, Lee HJ, Ha TK, Lee KG. Effect of normal saline irrigation on attenuation of shouldertip pain and on $\beta$-endorphin levels after laparoscopic cholecystectomy. Journal of Laparoendoscopic Advanced Surgical Techniques 2012 May; 22(4): 311-4.

9. “WHO Model List of Essential Medicines”. World Health Organization. October 2013. Retrieved 22 April 2014.

10. Lexicomp. “Bupivacaine (Lexi-Drugs)”. Retrieved 20 April 2014.

11. Joris J, Thiry E, Paris P, Weerts J, Lamy M. Pain After Laparoscopic Cholecystectomy: Characteristics and Effect of Intraperitoneal Bupi-vacaine. Anesthesia \& Analgesia 1995; 81(2): 379-84.

12. Cunniffe MG, McAnena OJ, Dar MA, Calleary J, Flynn N. A prospective randomized trial of intraoperative bupivacaine irrigation for management of shoulder-tip pain following laparoscopy. American Journal of Surgery 1998; 176(3): 258-61.

13. Esmat ME, Elsebae MM, Nasr MM, Elsebaie SB. Combined low pressure pneumoperitoneum and intraperitoneal infusion of normal saline for reducing shouldertip pain following laparoscopic cholecystectomy. World Journal of Surgery 2006; 30(11): 1969-73.

14. V. Kasiulevicus, V. Šapoka, R. Filipavicute. Sample size calculation in epidemiological studies. Gerontologija 2006; 7(4): 225-31. 